\title{
Incidência de doenças em cebola armazenada na região do alto vale do Itajaí/SC
}

\author{
Lauri João Marconatto ${ }^{1}$, Henrique Soares Koehler ${ }^{1}$, Leandro Luiz Marcuzzo ${ }^{2}$
}

${ }^{1,2}$ Universidade Federal do Paraná- UFPR, Programa de pós-graduação em produção vegetal, CP 19061, CEP 81531-990, Curitiba, PR, ${ }^{2}$ Instituto
Federal Catarinense - IFC/Campus Rio do Sul, CP 441, CEP 89.163-356, Rio do Sul, SC.
Autor para correspondência: Leandro Luiz Marcuzzo (leandro.marcuzzo@ifc.edu.br)
Data de chegada: 29/04/2016. Aceito para publicação em: 03/02/2017.

$10.1590 / 0100-5405 / 2172$

\section{RESUMO}

Marconatto, L.J.; Koehler, H.S.; Marcuzzo, L.L. Incidência de doenças em cebola armazenada na Região do Alto Vale do Itajaí/SC. Summa Phytopathologica, v.43, n.3, p.243-245, 2017.

Doenças são comuns em cebolas armazenadas, porém não existe levantamento especificando a causa e tão menos os níveis de incidência. Mediante a isso, esse trabalho teve como objetivo identificar a causa e os níveis de doenças no armazenamento de duas cultivares e duas classes de cebola.Nas safras 2014 e 2015, na região do Alto Vale do Itajaí/SC foram coletadas amostras com 27 bulbos em 29 produtores da cv. Epagri 362 - Crioula ou da cv. Empasc 352- Bola Precoce, tanto para classe 3 como para classe 4 . As cebolas foram armazenadas com ventilação natural durante 140 dias e a cada 28 dias foram avaliadas quanto a ocorrência de doenças através da sintomatologia e dos níveis de incidência. Constatou-se que a incidência de podridão de Sclerotium rolfsii foi inferior a 2,7\% e do mofo preto (Aspergillus niger) foi de $24,8 \%$ e $6,6 \%$ respectivamente em 2014 e 2015. Já na podridão mole (Pectobacterium carotovorum subsp. carotovorum) e podridão de escamas (Burkholderia cepacia) a incidência foi de $45,4 \%$ e $30,9 \%$ e de $50,7 \%$ e $45,3 \%$, respectivamente em 2014 e 2015. Os resultados obtidos visam à busca de soluções para reduzir os danos que ocorrem durante o armazenamento de cebola na região do Alto Vale do Itajaí/SC.

Palavras-chave: Allium cepa, Pós-colheita, fitopatógenos.

\section{ABSTRACT}

Marconatto, L.J.; Koehler, H.S.; Marcuzzo, L.L. Incidence of diseases in onion stored in the region of Alto Vale do Itajaí, Santa Catarina State, Brazil. Summa Phytopathologica, v.43, n.3, p.243-245, 2017.

Diseases are common in stored onions, but there is no survey specifying the cause and even the incidence. Thus, this study aimed to identify the cause and the disease levels in the storage of two cultivars and two categories of onion. In the crop seasons 2014 and 2015, in the region of Alto Vale do Itajaí, Santa Catarina State, Brazil, 27 bulb samples were collected from 29 onion farmers and included the cultivar Epagri 362 - Crioula or the cultivar Empasc 352 - Bola Precoce, for both category 3 and category 4 . Onions were stored under natural ventilation for 140 days and at every 28 days they were evaluated for occurrence of diseases based on symptoms and levels of incidence. Incidence of southern blight caused by Sclerotium rolfsii was less than $2.7 \%$ and that of black mould (Aspergillus niger) was 24.8\% and 6.6\% in 2014 and 2015, respectively. For soft rot (Pectobacterium carotovorum subsp. carotovorum) and sour skin of onion (Burkholderia cepacia), incidence was $45.4 \%$ and $30.9 \%$, and $50.7 \%$ and $45.3 \%$ in 2014 and 2015, respectively. The obtained results aim at finding solutions to reduce the damage that occurs during onion storage in the region of Alto Vale do Itajaí, Santa Catarina State, Brazil.

Keywords: Allium cepa, postharvest, phytopathogen.

Mundialmente a cebola (Allium cepa L.) é a terceira hortaliça mais cultivada e o Brasil ocupa a $9^{a}$ posição com uma produção na safra 2015 de $1.445,883$ toneladas, onde deste total, Santa Catarina contribuiu com $23 \%$ da produção nacional, totalizando 339.441 mil toneladas (2). No estado, aproximadamente $80 \%$ desta produção concentra-se na região do Alto Vale do Itajaí, onde bulbos das cultivares Crioula e Bola Precoce são normalmente armazenados na propriedade, em estaleiros com ventilação natural, por um período de 60 a 120 dias, aguardando melhores preços na entressafra. No entanto, o Instituto CEPA estimou para a safra 2013 danos em torno de $27 \%$ da cebola armazenada nessas condições (3), volume de perdas inaceitáveis para a maioria dos produtos agrícolas.

Os principais danos que ocorrem durante o armazenamento de cebola têm relação com a pré-disposição ao desenvolvimento de doenças. Entre as doenças comumente encontradas estão a podridão mole causada por Pectobacterium carotovorum subsp. carotovurum, podridão de escamas por Burkholderia cepacia e o mofo preto por
Aspergillus niger $(1,4,7)$. Porém outras doenças já foram descritas em diversas regiões e condições climáticas causadas por Penicillium spp., Pseudomonas viridiflava, Enterobacter cloacae, Pantoea ananatis, Fusarium oxysporum f.sp. cepae, Botrytis allii, Rhizopus spp., Colletotrichum circinans e Sclerotium cepivorum $(1,8)$. Estes fitopatógenos apresentam características sintomatológicas especificas e podem ser encontrados associados no mesmo bulbo.

Como não se dispõe de um levantamento sistemático para constatar a ocorrência dessas doenças, neste trabalho o objetivo foi identificar as causas e os níveis de incidência em bulbos armazenados em ventilação natural, agrupados de acordo com a sintomatologia, tanto para as classes 3 e 4 como para as cultivares Crioula e Bola Precoce na Região do Alto Vale do Itajaí/SC.

O trabalho foi realizado armazenando por 140 dias, bulbos com diâmetros entre 51 e $70 \mathrm{~mm}$ (classe 3) e entre 71 e $90 \mathrm{~mm}$ (classe 4) das cultivares 'Epagri 362' (Crioula) e 'Empasc 352' (Bola Precoce), coletados em diferentes propriedades nos municípios de Alfredo 
Wagner, Chapadão do Lajeado, Imbuia, Ituporanga, Leoberto Leal e Vidal Ramos, ambos na região do Alto Vale do Itajaí, Santa Catarina, durante a primeira quinzena de 2014 e de 2015.

Das amostras de 29 produtores, dezenove eram da cv. Bola Precoce e outros dez da cv. Crioula. As amostras de bulbos sadios foram coletadas aleatoriamente, armazenadas em sacos ou a granel a uma profundidade de até $20 \mathrm{~cm}$, em três seções do armazém, divididas proporcionalmente ao total armazenado, que variou de 35 a 450 toneladas. As amostras de cada seção foram compostas de nove bulbos, totalizando 27 para ambas as classes de cada cultivar.

As amostras foram armazenadas individualmente dentro de caixas plásticas vasadas em ambiente com ventilação natural, por 140 dias. $\mathrm{O}$ armazenamento foi realizado no armazém da Estação Experimental da Epagri de Ituporanga - SC, localizado ( $27^{\circ} 25^{\prime} 07^{\prime}$ ' S; 49 $38^{\prime} 46^{\prime \prime} \mathrm{W}$, $484 \mathrm{~m}$ de altitude) com médias interna ao armazém para o período de armazenagem de 27 de janeiro a 16 de junho, de temperatura $\left(19,8^{\circ} \mathrm{C}\right.$ e $\left.19,5^{\circ} \mathrm{C}\right)$ e umidade relativa do ar $(82,6 \%$ e $88,9 \%)$ respectivamente para 2014 e 2015. A cada 28 dias os bulbos doentes foram classificados de acordo com os sintomas apresentados externamente. O mofo preto foi identificado pela formação da eflorescência negra na superfície do bulbo e abaixo da primeira túnica e a ocorrência da podridão de S. rolfsii pela presença dos escleródios na superfície do bulbo. Os sintomas internos foram visualizados através do seccionamento longitudinal do bulbo e a identificação da podridão de escamas foi através das escamas externas com aparência úmida e amarelada com desagregação de minúsculos agregados e de odor avinagrado. Já a podridão mole foi identificada pelas escamas internas estarem deterioradas, apresentado uma coloração amarelo-amarronzada com odor fétido. Os sintomas foram comparados conforme literatura $(1,4,7)$ e após isso os bulbos eram eliminados da amostra. $\mathrm{O}$ cálculo percentual da incidência tomou como base o total das ocorrências nas amostras das classes e cultivares, tanto para cada avaliação como para o total de todo período. Quando da ocorrência de mais de um sintoma no mesmo bulbo, foi considerado na análise do percentual da incidência para cada doença.

Foi identificado o mofo preto causado por A.niger, Podridão de $S$. rolfsii, podridão mole incitada por $P$. carotovorum subsp. carotovorum e podridão de escamas por B. cepacia nos dois anos de avaliação.As proporções das doenças apresentaram variações entre as safras 2014

Tabela 1. Incidência (\%) de doenças em cebola armazenada de diferentes classes da cultivar Crioula e Bola precoce. Epagri/E.E. Ituporanga, 2014/2015

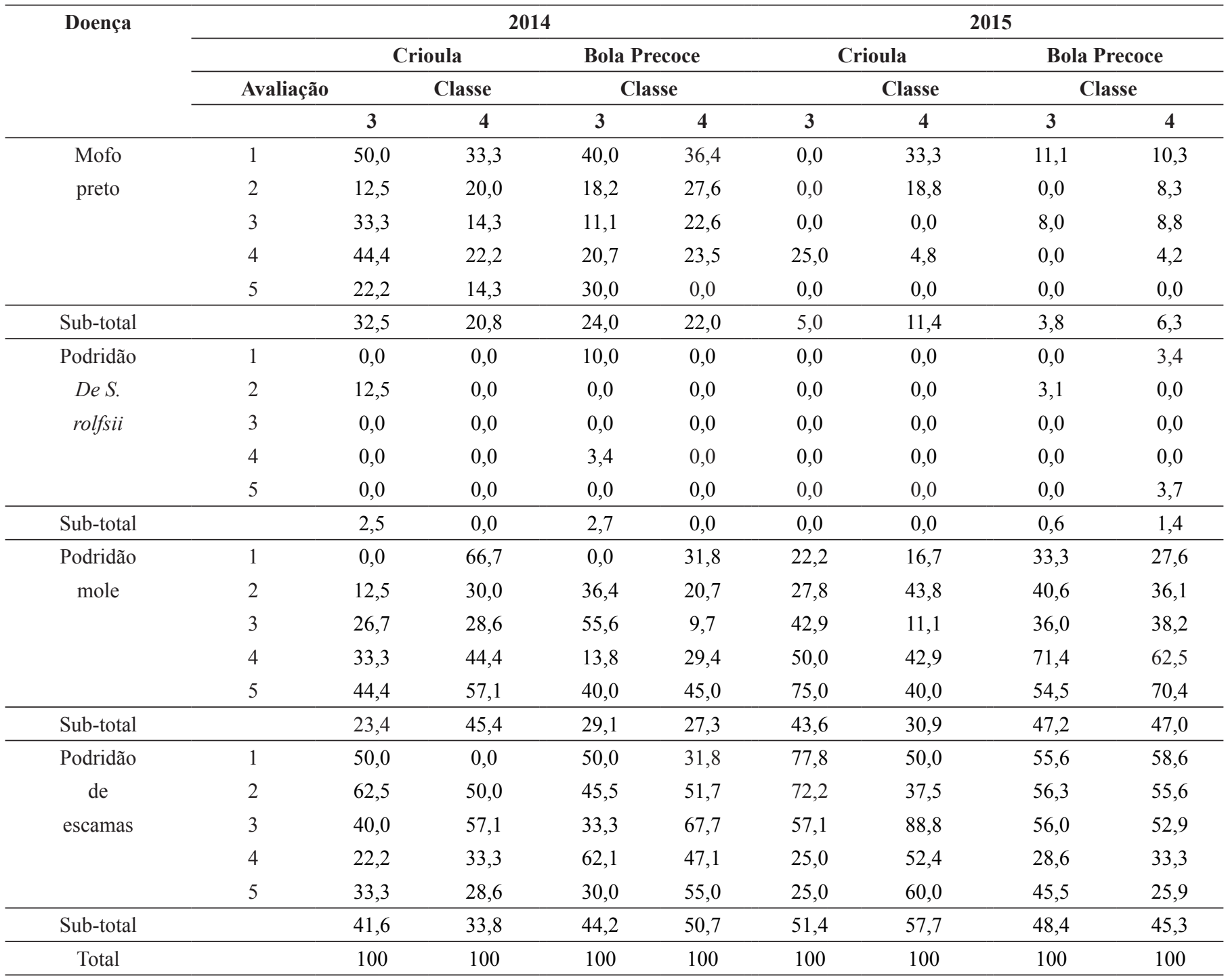


e 2015. Da mesma forma não houve um padrão entre as incidências quando consideradas as classes ou cultivares (Tabela 1).

A colheita da safra 2015 foi bastante afetada por chuvas, onde a cv. Crioula, teve em média 13,2 dias para cura em campo e recebeu em média 7,2 dias de chuvas, já a cv. Bola Precoce teve em média 11,5 dias para cura em campo e recebeu em média 1,8 dias de chuvas no período de cura. Para a safra 2014, a cv. Crioula, teve em média 12,3 dias para cura em campo e recebeu em média 3,6 dias de chuvas, já a cv. Bola Precoce teve em média 11,5 dias para cura em campo e recebeu em média 1,6 dias de chuva no período de cura, demonstrando que a intensidade de chuvas é maior no período da cura da cv. Crioula que é mais tardia.

O mofo preto teve incidência superior no ano de 2014 para todas as amostras (Tabela 1), com média de $24,8 \%$, enquanto para safra 2015 a média foi de $6,6 \%$. Esta diferença demonstra uma relação inversa com o número de chuvas durante a cura.A alta incidência do mofo preto causado por A. niger está de acordo com Sang et al. (5), que também constataram a incidência de $63,9 \%$ em cebolas que estavam em armazenamento e foram comercializadas na Coréia do Sul.

A ocorrência da podridão de $S$. rolfsii durante a safra 2014 foi proporcionalmente baixa, mas destaca-se a não ocorrência para a classe 4 tanto da cv. Bola Precoce quanto para a cv. Crioula, enquanto que para a para a classe 3 houve a ocorrência de $2,7 \%$ e 2,5\% respectivamente. Na safra 2015 não houve incidência para a cv. Crioula, já para cv. Bola Precoce, $0,6 \%$ para classe 3 e 1,4\% para classe 4 (Tabela 1 ).

A podridão mole com exceção da Classe 4 da cv. Crioula, apresentou incidência de $45,4 \%$ e $30,9 \%$ respectivamente para safra 2014 e 2015 (Tabela 1), a incidência foi maior na safra 2015 em decorrência do maior número de dias de chuvas durante a cura.

Para a podridão de escamas a incidência foi maior na safra 2015, com exceção para a Classe 4 da cv. Bola Precoce, com50,7\% e 45,3\% respectivamente para safra 2014 e 2015 (Tabela 1). Wordell Filho et al. (6) constataram a incidência de podridão de escamas em até $16 \%$ dos bulbos da cultivar Crioula da classe 2, 3 e 5 após cinco meses de armazenamento em estaleiro de ventilação natural, porém não caracterizou o tempo de cura e ocorrência de chuva durante o período.

O levantamento da incidência de doenças em bulbos de cebola serve de subsidio de qual cultivar e classe é mais afetada, evidenciando a necessidade de manejo durante a pré-colheita e cura para reduzir os danos encontrados durante a armazenagem de cebola na região do Alto Vale do Itajaí/SC.

\section{AGRADECIMENTOS}

Os autores agradecem à Capes, pelo financiamento parcial do trabalho e a Epagri - E.E Ituporanga por disponibilizar parte do armazém onde foram estocadas as amostras.

\section{REFERÊNCIAS}

1. Conn, K.E.; Lutton, J.S.; Rosenberg, S.A. Onion disease guide. St. Louis: Seminis, 2012. Disponível em: <https://www.seminis.com/SiteCollectionDocuments/Onion-Disease-Guide.PDF>.Acesso em: 02 fev. 2014.

2. IBGE - Instituto Brasileiro de Geografia e Estatística. Indicadores IBGE: estatística da produção agrícola, setembro de 2016. Brasília Disponível $\mathrm{em}:<\mathrm{ftp}: / / \mathrm{ftp}$. ibge.gov.br/Producao_Agricola/fasciculo_Indicadores_IBGE/ estProdAgr_201503.pdf.>.Acesso em: 14 fev. 2017.

3. ICEPA - Instituto de Planejamento e Economia Agrícola de Santa Catarina/ EPAGRI. Dados e Informações - Balanço de oferta e demanda - safras - 2012/13. Florianópolis: Epagri/Cepa, 2014. Disponível em <http:// http:// www.epagri.sc.gov.br/?page_id=3210>.Acesso em: 22 fev. 2016.

4. Massola Jr. N.S.; Jesus Jr. W.C.; Kimati, H. Doenças do alho e cebola. In:Kimati H.; Amorim, L.; Bergamin Filho, A.; Camargo, L.E.A.; Rezende, J.A.M (Ed.). Manual de fitopatologia. 4. ed. São Paulo: Ceres, 2004. v. 2, cap. 9, p.53-63.

5. Sang, M.K.; Han, G.D.; Oh, J.Y.; Chun, S.C.; Kim, K.D. Penicillium brasilianum as a novel pathogen of onion (Allium cepa L.) and other fungi predominant on market onion in Korea. Crop protection, Oxford,v.65, p.138-142, 2014.

6. Wordell Filho, J.A; Martins, D.A; Stadnik, M.J. Aplicação foliar de tratł amentos para o controle do míldio e da podridão-de-escamas de bulbos de cebola. Horticultura Brasileira, Brasília, v.25, n.4, p.544-554, 2007.

7. Wordell Filho, J.A.; Boff, P. Doenças de origem parasitária. In: Wordell Filho, J. A.; Rowe, E.; Gonçalves, P.A.S.; Debarba, J.F.; Boff, P.; Thomazelli, L.F. Manejo Fitossanitário na cultura da cebola. Florianópolis: EPAGRI, p.19-162, 2006.

8. Zaid,A.M.;Bonasera,J.M.;Beer,S.V.OEM- a new medium for rapid isolation of onion-pathogenic and onion-associated bacteria. Journal of microbiological methods. Bethesda, v.91, n.3, p.520-526, 2012. 